\title{
Methodological and Psychological Aspects of Education for Sustainable Development in Russia with Regard to International Cooperation
}

\author{
Natalya Kuzhanova, Tatyana Klets \\ Pskov State University, Faculty of Engineering and Construction Technologies. Address: Leo Tolstoi 4, Pskov, \\ Russia.
}

\begin{abstract}
In 2004 the European Economic Commission developed the Strategy of Education for Sustainable Development (ESD). The aim of the strategy is the promotion of education for sustainable development and its inclusion in the system of formal and informal education. The authors propose the measures for the acceleration of ESD distribution at the international level because international cooperation in education can be considered as a contribution of countries to the implementation of global transition to sustainable development. The authors' concept of the phenomenon of ecological consciousness and the conditions of its formation are considered. The main problems of ESD efficiency are defined and criteria for its evaluation are offered. Integral features of the personality as an indispensable component of ESD are described.
\end{abstract}

Keywords: ecological consciousness, ecological culture, education for sustainable development, environmental awareness.

\section{INTRODUCTION}

Nowadays sustainable development (SD) in education is generally understood as the further stage of ecological education [1].

It is known that in 2014 the European Economic Commission developed the Strategy of Education for Sustainable Development (ESD) [2]. The main objectives of the strategy are as follows:

- assistance to sustainable development by formal and informal training;

- education of teachers who afterwards include questions of SD in the courses delivered;

- strengthening international cooperation in the field of SD.

It is supposed that the specialists who have acquired principles of sustainable development will perform their professional activities according to them. To achieve this goal, personal and professional qualities of a future specialist should be based on three obligatory components. They are:

- the amount and level of proficiency in the generalized knowledge and ideas of surrounding natural and social reality, necessary for forward and balanced development of the "person-society-nature" system;

- the availability of competences in acceptance of professional solutions on the basis of complete product life cycle or activities. This period covers production and conversion of raw materials in a product, sale, use and servicing of a product and comes to an end with placement of production wastes and consumption taking into account transport flows during the whole cycle (ISO 14040 and 1441 standards);

- the created consciousness reflecting valuable line items of the personality based on ideology of sustainable development.

It is obvious that the methodology of ESD is in direct dependence on the level of consciousness of a future specialist, on how this level corresponds to those moral and valuable reference points which are set by the principles of sustainable development [3].

In this paper an attempt to give objective characteristics of the phenomenon of a human person that corresponds to the present stage of the Russian society development is made.

\section{MATERIALS AND METHODS \\ The initial position for characterizing} consciousness of sustainable development is such a system of attitudes of the subject towards objective reality which 1) is based on a noosferizm [4] relying on a post-nonclassical paradigm of science and society development; 2) allows to use synergy 
approach in activity; 3) creates high motivational activity on overcoming anthropogenous crises through development when a new, higher level of dynamic balance with the environment is established; 4) considers culture as a factor which compensates constantly increasing tool and technological capabilities and supports internal control over manifestation of society and each person's aggression. It is culture that assimilates experience of anthropogenous catastrophic crashes and develops effective management models of social and natural processes [5].

The level of consciousness of a person is determined by the environment in which he lives, feels, creates or destroys.

The two components of the environment - sociocultural and educational - are considered to be the most important for a future specialist. At the same time, objects, relations, traditions, established values, rules and regulations, symbols cultivated and supported by all members of society (or by its absolute majority) refer to the socio-cultural environment.

Researches show [6] that a real situation in the Russian society, the technological level of production processes, socially snugged rules of conduct, ordinary ideas of relations of a person with the environment correspond to psychology of so-called "industrial or technocratic society" in Russia. It means that ecological content of the acts made to a natural environment is not actualized by people.

Consumer meanings are more urgent. Anthropocentrism is shown in the attitudes towards other living beings. Possibilities of satisfaction of communication requirement with the nature are connected with the expansive appropriating behaviour forms. Two mutually exclusive bases very often get on in the identity of the modern person: he may be, hypothetically, "the most active friend of the nature" in off-duty hours and, at the same time, at work, being submitted to logic of production process, may cause ecological damage. According to some data [7], the level of development of the intellectual and strong-willed parts of consciousness for sustainable development in Russia is yielded by more than twice to the average level of economically developed countries.

In general, at this stage the social and economic situation and the level of public consciousness testify that problems of SD don't become essential and necessary for most of Russians and, consequently, for students. At the same time, Russia declared the commitment to the ideas and principles of SD but not to the detriment of the national interests [8].

What is ESD methodology? For its development it is necessary to outline a circle of the main problems in its development, a theoretical basis and criteria for evaluation of its efficiency. We will briefly describe each of the designated line items.
The main problems of efficiency of ESD are seen in the following:

1) The problem of a ratio of components of education.

At present, geographical and ecological components prevail in ESD. A lot of questions are put in a considerable number of training courses, but significantly less number of answers is given.

These questions are:

- what should the world order be like?

- in what way to prevent emergence and distribution of terrorism?

- what are universal criteria of society of reasonable consumption?

- what is the interrelation of democracy and development in countries with different culture?

At the same time, economic (quality of life, SD indicators, etc.), socio-political (environmental policy at the global, regional, local levels), social-andecological (world outlook SD bases, ethics of life, behavior of reasonable consumption, etc.) components remain insufficiently worked out.

2) Elitism problem.

Unfortunately, questions of sustainable development and values inherent in it concern and are significant for very limited number of students so far.

3) The problem of mentality and traditions is closely connected with the aforesaid problem.

Formation of sustainable development isn't valuable as it has no pragmatic component. At the same time, our students prefer to get a specific education which can give them means of livelihood in future. Such is a mental feature of our students. The ideas of sustainable development, "social justice" haven't been personal values for them yet.

4) Customer's problem.

In Russian economy there is no order for a position of a specialist in sustainable development so far. The modern period of development is characterized by the fact that the need for specialists in engineering environment protection increases. It is necessary to recognize that engineering environment protection and education for sustainable development are not identical concepts. Students of ecology, finishing education in a higher education institution, generally own knowledge and skills of the technologies of purification of air and water, calculated parameters connected with impact on the environment (waste, physical factors, etc.), the regulatory base of technogenic impact, etc. Meanwhile, it is necessary to consider complete product life cycle or activities in the SD course. This cycle covers production and conversion of fossil raw materials, conversion of raw materials in a product, sale, use and servicing of a product, placement of production wastes and consumption taking into account transport flows during the whole cycle [9]. 
5) Shortcomings of theoretical bases of sustainable development.

These shortcomings result in difficulties of development and promotion of SD training courses.

The most essential shortcomings of SD theory development are:

- the lack of the single theory of stability of the biosphere;

- the lack of the theory of justice;

- uncertainty of a ratio of the concepts "stability-variability";

- shortcomings of the applied development indicators;

- the availability of a general relativistic approach.

6) Insufficiency of coordination of education for sustainable development at the international level.

This problem is characterized by:

- the lack of a databank of SD education at the international level;

- the recognition of diplomas on SD by higher education institutions of different countries;

- the lack of the unified criteria for a quality evaluation of SD training courses [10].

\section{RESULTS AND DISCUSSION}

What are criteria to estimate education for sustainable development?

It is possible to make an attempt to estimate quality of educational programs via ESD indicators which can be the following:

- to what extent development of education in the field of sustainable development is supported politically and organizationally by official structures;

- how sustainable development through formal, informal and unofficial studying is supported;

- competence of teachers in the field of sustainable development that is necessary for training;

- the availability of adequate training materials;

- the support of researches in the field of sustainable development and promotion of education in this field;

- coordination of education for sustainable development at the international level, its structure, function and the principles of interaction;

- strengthening of cooperation at all levels by training in the field of sustainable development at the regional level;

- the integration of the SD ideas into disciplines of educational standards on various specialties. At the same time the closest attention should be paid to engineering specialties as specialists in production and technology render the greatest anthropogenous load on the environment by their professional activity.

This list can be continued.
How can acceleration of process of ESD distribution be achieved in the nearest future?

Firstly, it is necessary to realize accurately: at present it is impossible to persuade all members of the society, and, above all, its future active members - modern students - to share and profess the principles of sustainable development in their professional and everyday life. Purposeful search of that part of youth to which the declared principles are closest and clear is necessary. These may be graduates of specialized classes or profile educational institutions with an ecological orientation.

Secondly, teaching and educational process should be organized on the conscious and comprehensive analysis of the ideas and principles of sustainable development taking into account, on the one hand, strategic objectives of all mankind - to survive and keep the habitat for future generations, and, on the other hand, to provide for Russia the worthy place in future.

Thirdly, professional activity training should be arranged on the basis of resource and energy-saving technologies with forming the system of professional thinking based on the idea that environmental problems of the entity or activity should be solved in a pollution source, but not "at the end of a pipe". It means transfer of the center of gravity from reactive to preventive approaches [11].

What result of such methodological approach to sustainable development in education can be seen?

It is slow, but steady increase of such members of society who realize and understand that salvation of mankind (however pathosly it may sound) is in the change of the concept of life of each person. It should bring real dividends in combination with reasonable environmental policy of the state. According to the theory of the social diffusion applicable to distribution of new habits and regulations of life, the presence of $10-12 \%$ of members of society is enough in order that these changes could begin. After achievement of a threshold of $30 \%$ these changes become irreversible.

The task of the present stage is to achieve a $12 \%$ result.

To build the educational process in the logic of sustainable development at Pskov State University, the socio-pedagogical system of forming students' ecological culture has been designed and implemented for a number of years. The process of this culture formation is a syncretic phenomenon, therefore it is prolonged for the entire period of study at the university and represents the synthesis of the following activities of a future specialist: 1) the initiation of information that constitutes the essence of sustainable development on the basis of experience an assimilation of cross-cultural values of an ecological orientation for the formation of a primary basic worldview; 2) the adoption of sustainable development principles in the process of general 
professional training; 3 ) the formation of professional competences on the basis of the implementation of academic professional activities. All these elements are included into scientific and educational project activities in professional and social aspects. This is how the lifestyle is formed that is understood as the integral formation of the personality based on the environmental consciousness and ecological style of thinking [12].

\section{CONCLUSION}

International cooperation in education for the benefit of sustainable development qualitatively influences the development of education in this area in Russia in general and in certain regions (especially if these regions are the territories of the adjacent states, and environmental problems of these states have general history and roots). The cooperation in the field of education can be considered as a component of the contribution of countries to the implementation of processes of global transition to sustainable development.

As we know, much work on forming an education system for sustainable development is conducted in the world. In developed countries the result of this process is an impressive development of its institutional bases and the state support ensuring.

This experience is especially interesting to the countries with the developing and transitional economy. Experience of developed countries in the sphere of ecological education for sustainable development can push economically unstable states to creation and development of the system of environmental protection, to active promotion of the ideas of sustainable development among the population, to distribution of effective measures for achievement of safe activity and balance of economy and ecology which is the basic criterion of sustainable development [13].

\section{ACKNOWLEDGEMENTS}

This study was partly supported by the Baltic University Programme that focuses on issues of sustainable development in the Baltic Sea region and supervises university co-operation. The Programme is co-ordinated by a secretariat at Uppsala University. Pskov State University is a member of this international cooperative project.

\section{REFERENCES}

[1] N. I. Kuzhanova, Forming of ecological culture of students at the higher technical school. Pskov: POIPKRO, 2004, 292 p.

[2] N. P. Komendantova-Amann, "Awareness of need for sustainable development as one of the most important values of society", Culture Horizons: SPb: SPbSPU publishing house, 2005.

[3] T. V. Ivanova, "Ecological values in public consciousness," Psychology Questions, Vol.3, 2009.

[4] A. I. Subetto, Noosferizm. SPb, 2001. 591 p.

[5] N. I. Kuzhanova, "The importance of ecological consciousness in the strategy of education for sustainable development", Economic Innovations, Vol. 53.Odessa, 2013, pp. 129-139.

[6] I. V. Kryazh, "Psychosemantic research of ordinary ecological representations", Psychology Questions, Vol.1, 1998.

[7] V. V. Bakharev, Ecological culture as factor of sustainable development of society. Ulyanovsk: ULGU publishing house, 1999,593 p.

[8] N. I. Kuzhanova, "Cross-border cooperation in the field of ecological education", Environmental, economic and sociocultural preconditions of cross-border cooperation in the Baltic region", Proceedings, Pskov, 2012, pp. 12-23.

[9] M. R. Kononenko, "Foreign experience of education in the field of ecological management and its use in RGGMU", Actual issues of teaching a university course "Ecological management". SPb: RGTMU publishing house, 2003, 242 p.

[10] S. D. Deryabo and V. A. Yasvin, Ecological pedagogics and psychology. Rostov-on - Don, 2008, 348 p.

[11] E. V. Girusova, Ecology and economy of nature use. M: UNITY, 2007, $591 \mathrm{p}$

[12] N. I. Kuzhanova, "To the question of methodology of education for sustainable development in Russia based on international experience", Proceedings, Pskov, 2013, pp. 3741 .

[13] Lars Ryden, Pawel Migula, and Magnus Anderson, Environmental Science. Uppsala:The Baltic University Press, 2003. 